\title{
Study on the route and Countermeasures of the development of tourism e-commerce in Silk Road
}

\author{
Ding Chen ${ }^{1, a}$ \\ ${ }^{1}$ E-commerce College Of Business, Xi’an International University, Xi’an Shaanxi, China, 710077
}

Keywords: Silk Road tourism; e-commerce; problems; development path

\begin{abstract}
Silk Road Economic Belt is an important part of regional economic development in our country, many provinces along the Silk Road Route in central and Western China, and West Asia, Eastern Europe and other countries. Therefore, the tourism resources are very rich. In the era of the Internet economy, e-commerce has become a new way of constructing tourism management model, based on the construction of network platform, tourism can not only reduce the operating costs of enterprises, also to promote the development of the Silk Road Tourism economy. Therefore, this article embarks from the silk road traveling electronic commerce development present situation, as well as its existence question, carries on the inquisition to the related development path and the development countermeasure.
\end{abstract}

Introduction: In 2013, the general secretary Xi Jinping's speech at the Steiner Zal University of Kazakhstan Nazarbayev, puts forward the concept of "Silk Road Economic Belt". Silk Road Economic Belt, is a new form of regional economic development based on the concept of the ancient Silk Road on the East, it is connected with the Asia Pacific Economic Circle, the West communication with developed European economic circle, is considered to be the "big economic corridor in the world's longest and most potential". The silk road is the main route connecting Asia economic and trade of the ancient China, it through the inheritance and development of thousands of years, even after the interruption, but contains the humanities spirit in the history of the polish is more thick long. To enter a new period of development, facing the increasingly complex international environment, we should pick up the Silk Road Communication politics, economic and cultural functions, make it revitalized in the new market conditions. Tourism e-commerce is the last century was born in 80s in the Internet under the condition of a new kind of tourism management mode, and the silk road connecting many provinces of Northwest China, is rich in tourism resources, the development of electronic commerce under the background of the humanistic spirit of the Silk Road to re build the tourism industry has become the main direction of the Midwest. The development of modern tourism.

\section{The Silk Road tourism e-commerce development status and development issues}

With the increasing popularity of tourism tourism e-commerce, online travel booking has increased year by year, according to the thirty-ninth "China Internet Network Information Center released statistical report on Internet development China" shows: as of December 2016, online booking flights, hotels, train tickets or tourist products users reached 299 million, compared to 2015 at the end of growth 39 million 670 thousand, the growth rate is 15.3\%. And the expanding reservation rate indicates the huge market potential of tourism e-commerce, and the Silk Road tourism will inevitably get new development opportunities under this market condition.

The macro policy environment for the better

The silk road not only contains enormous tourism resources, it contains profound cultural connotation, and carry out the "Silk Road" is a response to the national "12th Five-Year plan" for "cultural tourism" requirements, relying on the Silk Road cultural background, let tourism become a process to experience the cultural charm the. In addition, in the Internet economy, China put forward the development idea of "Internet plus", and through the transformation of government 
functions, to promote the construction and improvement of tourism e-commerce platform, so as to promote the development of the Silk Road Tourism e-commerce.

Social media play a huge role in promoting

The development and popularity of social media, let the whole society into a new social network, in social media, individuals can share, reprint, comments on the tourism resources score, while the potential consumers can make decisions according to the evaluation of tourism resources, for example, users can query the information in the bean, TripAdvisor etc. the score of professional platform, as their reference, and the development of the Silk Road tourism e-commerce in promoting social media interaction, get new development opportunities.

With the gradual increase in the level of national income, people in the pursuit of the spiritual life is more and more strong, tourism as a relax, increase knowledge, broaden their horizons and important leisure projects gradually favored by consumers. In recent years, the rapid development of China's tourism industry, occupy in GDP proportion is increasing, which has brought new opportunities for the development of tourism e-commerce, and the Silk Road as an important part of cultural tourism, gradually use cultural resources to attract more tourists to participate.

Tourism electronic commerce development needs the support of the Internet, e-commerce development in the traditional computer environment is relatively slow, and in the growing popularity of smart mobile devices under the condition of the development of electronic commerce has entered into a new stage, such as in 2016299 million people booking travel online, 262 million is to complete the transaction through mobile phone. The advantages and convenience of mobile intelligent terminals have become the main direction of the development of e-commerce. For the Silk Road, the advantages of mobile intelligent terminals will gradually penetrate into the development of tourism.

\section{Development issues}

Although the tourism resources along the Silk Road are very developed, but the level of development is difficult to meet the needs of the development of e-commerce tourism. In Xi'an, Xinjiang and other provinces are not only well-known tourism resources at home and abroad, and the infrastructure has been increasingly improved, but other provinces along the Central Asian countries and tourism resources, is still in the early stages of development, the tourism environmental bearing capacity is not high, the economic development is relatively slow, and there are certain environmental problems.

Under the condition of market economy, marketing is essential, but in the process of the Silk Road tourism e-commerce development, the relevant departments of the marketing mechanism is still a continuation of the traditional propaganda mode, not only the lack of market positioning of tourism resources, but also the lack of information collection and analysis of potential consumers, in the context of large data the development of information, and e-commerce are closely linked, and the Silk Road tourism development if not play to the advantage of information resources will inevitably encounter a bottleneck in marketing.

With the advent of the Internet at the beginning of the Internet, with the advent of the information age, the development of e-commerce, consumer information protection in electronic transactions is more important. But at present the Silk Road tourism e-commerce in the aspect of safety management is not absolutely safe and reliable, customer information is not only a huge loss of personal property, but also makes the tourism business development into a crisis of confidence, thus affecting the tourism e-commerce market reservation rate.

The silk road runs through Asia and Europe, with only more than 4000 kilometers of domestic lines. But because of the imbalance of regional economic development, the traffic inconvenience, thus restricting the smooth development of tourism resources, such as Xi'an province development status of inland economy in China better, in the air and land transport development more perfect, but in Gansu, Qinghai, Xinjiang and other provinces, the only capital city traffic is convenient other remote area traffic is relatively backward, which largely restricts the development of tourism e-commerce. 
Although the proposed development of the concept of Silk Road Economic Zone to create a new market environment to promote the economic development of Tourism along the line, but from the point of view to build tourism brand, the development of the Silk Road tourism e-commerce still has not formed the scale, not the formation of the market influence of the brand, and even make a complete travel routes are difficult, therefore, the market development is very difficult to be recognized by consumers.

\section{Silk Road tourism e-commerce development path}

With the continuous development of Internet technology, and the popularity of mobile intelligent terminal, the tourism e-commerce will become the main mode of the future development of the tourism industry, the Silk Road as a tourist resource in China, its potential in the development of electronic commerce, the firm should determine the direction of development, a new development path, so as to continuously expand the Silk Road by electronic commerce tourism market. The route of development of the tourism e-commerce in the silk road is mainly reflected in the following points:

The essence of the tourism industry is a service industry, the development of the Silk Road tourism e-commerce should also follow the basic characteristics of the service industry, the use of third party platform to provide comprehensive, thoughtful and meticulous services for consumers. In the process of optimizing the service content, e-commerce platform to continuously improve the hand function, combined with the corresponding travel route, make feasible plan for tourists and tourism, combined with the characteristics of the tourism resources to provide differentiated services; on the other hand also should fine service module, will be transformed into a platform to promote the service content specifically, in order to improve the tourism e-commerce market reputation.

With the continuous development of tourism resources in China, people have become tired of stereotyped tourism content, and new discoveries in tourism have become an important goal for people to experience the fun of tourism. The development of individualized tourism provides a new opportunity for the development of the Silk Road tourism e-commerce, the construction of e-commerce platform, along the Silk Road should be combined with the characteristics of tourism resources, to provide different choices for tourists, so as to meet their individual needs, the use of personalized service to create a brand image.

The economic development of the Internet makes the possibility of win-win cooperation and competition in the market gradually increased, in the development of the Silk Road tourism e-commerce, tourism enterprises should be combined with the development trend of the modern market, and strengthen the communication between the joint and the upstream and downstream enterprises and similar enterprises, formed a certain benefit by expanding the scale, for example in the process of building the third party in the platform, we should strengthen the connection with the Internet payment platform, and through the information security protection system, improve the network transaction rate.

Although tourism e-commerce has great potential for development, but in the market economy, as a new thing, its development and expansion must rely on the power of capital. In the Silk Road tourism development, tourism enterprises should actively participate in the operation of the market, the basic law, and grasp the electronic trading market through financing, provide strong support for e-commerce platform operation, and continue to expand its influence in the tourism e-commerce market, create the Silk Road tourism brand image.

\section{The Silk Road tourism e-commerce development countermeasures}

In order to realize the standardized development of the tourism e-commerce in the Silk Road, the tourism route should be scientifically planned first. The relevant departments in the process of formulating development strategies of tourism e-commerce, on the one hand, to rely on the local tourism resources to develop distinctive tourist routes, to meet the personalized needs of tourists; on 
the other hand, the state should also strengthen the demonstration and guidance, regulate the tourism management by classification, to ensure the sustainable development of tourism resources.

A development of tourism resources along the silk road according to the scale, realize the integration of development, to promote the integration of tourism resources between different regions, optimization of regional traffic network, provide considerate service for tourists to travel; on the other hand, should also reflect the tourism e-commerce development characteristics, using the network development platform, to provide real-time the information recommendation for tourists, visitors can make timely access to local attractions, delicacy, accommodation, cultural characteristics and other information, to enhance the travel experience.

E-commerce platform is the main way to develop tourism resources along the Silk Road, in the process of building e-commerce platform, tourism enterprises should first do online information dissemination, constantly optimize the network information platform module, from the basic necessities of life, leisure and entertainment aspects to provide comprehensive information for tourists; secondly focus on security management platform, protection good customer information, to avoid information leakage effectively, provide a safe and reliable travel for tourists; finally, realize the communication and cooperation between travel agencies, the use of electronic platform, using the concept of win-win cooperation, promote the development of information exchange, online transactions.

The intangible cultural resources is relying on the advantage and the development of the Silk Road, along the Silk Road in the visitors can not only enjoy the tangible cultural landscape, but also can realize the intangible cultural heritage, and edify sentiment in the culture of. The Silk Road tourism e-commerce in the development, not only to cultivate special attractions, characteristics of products, should pay more attention to the mining of intangible culture, let visitors can Hair Coloring journey along the Silk Road to truly become a cultural tour.

Human resource management is an important factor affecting the development of the modern electronic commerce, on the Silk Road tourism development of electronic resources, tourism enterprises should consider from long-term development, speeding up the training of professional talents of e-commerce, improve the personnel information literacy, according to the development trend of modern electronic commerce, in line with the development of the Silk Road tourism industry development plan.

\section{Conclusion}

In short, in the new economic development situation, tourism and e-commerce has become an important step in promoting the transformation of the tourism industry. Silk Road Economic Belt led to the development of the tourism industry in the surrounding, but also provides the development space for the development of tourism e-commerce, e-commerce security vulnerabilities but rely on Internet technology to develop their own, and lack of tourism enterprises in the planning of tourism resources resulted in the development of tourism e-commerce in China is not smooth, and face new difficulties, we should strengthen confidence, difficulties, careful analysis of the reasons of the development of tourism e-commerce at present, and made the improvement from the system construction, technology development, human resources management, to promote the healthy development of the Silk Road Tourism e-commerce.

\section{References}

[1] Yuhua L I. Research on Countermeasures for Depth Development of Luoyang's Tourism Industry in the National Strategy of " One Belt and One Road"[J]. Journal of Luoyang Institute of Science \& Technology, 2017.

[2] Zhang Y, Wang Z Z, Chen Y F, et al. Research on Development Countermeasures of Xi'an Export-Oriented Economy Based on the "Silk Road Economic Belt" $\mathrm{J}]$. Journal of Xian University of Finance \& Economics, 2015. 
[3] YU Gong, ZHONG Yansen, School of Tourism, et al. A Study of the Situation and Problems of Guangzhou Cultural Tourism Industry and the Countermeasures[J]. Journal of Guangzhou University(Social Science Edition), 2014.

[4] Zhao Y Q, University X F. The Opportunities And Challenges of The Inbound Tourism Trade of Services In Xinjiang under the Background of “The Silk Road Economic Belt”[J]. Journal of Xinjiang Vocational University, 2016.

[5] Sun H, Dong Y, Li Y, et al. Research on the Silk Road Tourism Development from the Perspective of Tourist Destination[C]// International Conference on Future Computer Science and Education. IEEE Computer Society, 2011:75-79.

[6] Wang K. Countermeasures Study of Sustainable Development of Zhaoyuan Newport[J]. Journal of Heilongjiang Bayi Agricultural University, 2016. 